\title{
Analysis of Energy Characteristics of Rice and Coffee Husks Blends
}

\author{
Cuthbert F. Mhilu \\ College of Engineering and Technology (CoET), University of Dar es Salaam, P.O. Box 35131, Dar es Salaam, Tanzania
}

Correspondence should be addressed to Cuthbert F. Mhilu; cfmhilu@hotmail.com

Received 6 December 2013; Accepted 3 February 2014; Published 13 March 2014

Academic Editors: J. A. González and A. Ragauskas

Copyright (C) 2014 Cuthbert F. Mhilu. This is an open access article distributed under the Creative Commons Attribution License, which permits unrestricted use, distribution, and reproduction in any medium, provided the original work is properly cited.

Production of first generation biofuels using food crops is under criticism over sustainability issues on food security. Tanzania is showing active interest in developing second generation biofuels to deal with some of such issues, especially from the feedstock point of view. This paper reports work done to determine energy characteristics of rice and coffee husks. The results show that coffee husks have better energy quality than rice husks, while heating values of coffee are $18.34 \mathrm{MJ} / \mathrm{kg}$ and $13.24 \mathrm{MJ} / \mathrm{kg}$ for rice husk. Thermogravimetric analysis made for coffee husks blended rice husks at a ratio of $75: 25 \%$ vol. show better material degradation characteristics yielding low residual mass of $23.65 \%$, compared to $26.50 \%$ of char and ash remaining in pure rice husks. Derivative thermogravimetric analysis shows comparable hemicellulose degradation peak values of -11.5 and -11.2 and cellulose -3.20 and -2.90 in pure coffee and rice husks, respectively. In coffee and rice husks blends, substantial reductions of hemicellulose and cellulose peaks were observed. Use of coffee and rice husks blends applying high temperature gasification would reduce the latter's flammability, while increasing its flame retention characteristics, hence offering opportunities for production of clean syngas in a sustainable manner.

\section{Introduction}

1.1. Background and Goal. For many years, we have consumed fossil fuels with no worries about possible shortages, but, now, those same oil fields are running dry, while use of coal as a source of energy is also facing criticisms due to its contribution on environmental pollution. In view of this situation, there has been a growing impetus looking for alternative sources of energy for the future. Biomass based second generation biofuels could partly assist to resolve some of these issues, especially from the feedstock point of view for energy production applying various conversion methods to improve the combustion efficiency. The advantages of using biomass are obvious as this material, is generally left to rot or burnt in an uncontrolled manner, producing $\mathrm{CO}_{2}$ as well as smoke.

Most African countries are facing problems of inadequate access to modern sources of energy. The United Republic of Tanzania being one of the sub-Saharan African countries is showing active interest in the development of the second generation biofuels, especially from the feedstock point of view to address criticism over sustainability issues as well as arguments on food security arising from the production of 1st generation biofuels derived from food crops materials to replace the current use of petroleum products.

Use of biomass materials, referred to as the second generation biofuel, derived from agricultural wastes and forest residue and a number of fast growing trees, and grown specifically for energy purposes, could provide opportunities for nonfood based feedstock materials. Tanzania is endowed with biomass potential for energy production originating from forest plantations and agricultural wastes supported by the already existing infrastructure for their deployment [1].

The conversion of biomass materials to gaseous or liquid form of energy is known to be easier to handle and make applications. Varied schemes of processes for converting biomass into valuable fuels also exist. These include biological processes to make ethanol or methane and thermal processes to make heat, gaseous fuels, liquid fuels, and solid fuels. During the process, a variety of secondary products can also be produced from the liquid and gaseous fuels. In this form, 
TABLE 1: Estimated rice and coffee husks waste potential.

\begin{tabular}{lcccc}
\hline Waste & Primary product & Waste factor & $\begin{array}{c}\text { Primary product production } \\
\text { ('000 tones) }\end{array}$ & $\begin{array}{c}\text { Estimate amount of waste } \\
\text { ('000 tones) }\end{array}$ \\
\hline Rice husks & Paddy rice & 0.325 & $1,003.75$ & 326.22 \\
Coffee husks & Coffee seeds & 0.2 & 52.06 & 10.40 \\
\hline \multicolumn{2}{r}{} & Total & & 336.62 \\
\hline
\end{tabular}

TABLE 2: Rice and coffee husks materials blending ratios.

\begin{tabular}{lccccccc}
\hline Material & Blend 1 & Blend 2 & Blend 3 & Blend 4 & Blend 5 & Blend 6 & Blend 7 \\
\hline Coffee husks & $0 \%$ & $25 \%$ & $40 \%$ & $50 \%$ & $60 \%$ & $75 \%$ & $100 \%$ \\
Rice husks & $100 \%$ & $75 \%$ & 60 & $50 \%$ & $40 \%$ & $25 \%$ & $0 \%$ \\
\hline
\end{tabular}

because of added value, the derived fuels can be used to produce electricity.

This paper reports on work done to determine the energy characteristics of selected agricultural residues originating from rice and coffee husks. The study conducted thermogravimetric analysis to obtain information on thermodegradation behaviour of the biomass materials and their main components (hemicellulose and cellulose). Use of the derivative thermogravimetric (DTG) analysis has also been made in order to establish materials suitability for the production of clean syngas for electricity generation in a sustainable manner applying high temperature gasification technology.

1.2. Agricultural Residue Potential. Agriculture is the leading economic sector for Tanzania, and over $80 \%$ of the population living in rural areas depends mainly on agriculture for their livelihood. The country is endowed with abundant unutilized land since agriculture is dominated by small-scale subsistence farming, where out of 44 million hectares of the land suitable for agriculture, only 10.1 million hectares (23\%) are under cultivation. The untapped land resource provides therefore a huge potential for planting energy crops targeted for production of heat and power, transportation energy, and fine chemicals.

Experience gained on the country's agricultural activities shows that most of the agricultural products generate considerable amounts of waste which can be harnessed for energy production. However, the usefulness of the agricultural wastes will highly depend on their quality including economics of transportation against the technologies to be deployed. On the other hand, the energy content of different biomass materials differs depending on the level of their moisture content, which is known to affect the energy recovery process.

For the purpose of this study use has been made of selected agricultural residues originating from rice and coffee husks that are readily available in Tanzania, which offer the opportunity in the development of the second generation biofuels sector. An evaluation of the total amount of agricultural waste that originates from rice and coffee husks only as shown in Table 1 is estimated to reach over 336.62 thousand tones [1].

\section{Materials and Methods}

2.1. Feedstock Samples Preparation. The types of feedstock materials used in the study were collected as residues from large-scale farms located in the North Eastern part of Tanzania (Kilimanjaro Region) for the case of coffee husks, while rice husks were collected from the Southern Highlands part of Tanzania (Mbeya Region). The method adopted prior to gasification studies involves the preparation of feedstock samples to specified size and moisture content, followed by analysis of feedstock materials properties and determination of thermal degradation characteristics.

Initial reduction of moisture content in rice and coffee husks was made through sun drying, allowing grinding of the materials to be made to particles size of about $1 \mathrm{~mm}$. The obtained material samples were then dried under controlled conditions at $105^{\circ} \mathrm{C}$ for 1 hour in a VECSTAR 174799 furnace model F/L for further removal of the moisture. The dried rice and coffee husks material were then blended in accordance to the mixing ratios as indicated in Table 2 .

2.2. Analysis of Feedstock Materials Properties. Analysis of biomass samples properties was conducted to determine the amount of fuel energy that can be released per unit mass or volume when the fuel is completely burned (heating or calorific values, in $\mathrm{MJ} / \mathrm{kg}$ ). The heating values of the biomass samples were determined experimentally in accordance to the established ASTM D240 standard method using an autobomb calorimeter model: CAB001.AB1.C available at the Energy Engineering and Sciences Laboratory of the University of Dar es Salaam, Tanzania.

Loading of biomass samples of about $1 \pm 0.01 \mathrm{~g}$ into the bomb calorimeter was made and allowed to burn in the presence of oxygen pressurized to 30 bar inside a sealed container (bomb). The heat released from combustion was transferred to a mass of working fluid (water) that surrounds the container, allowing the heating values to be calculated, as the product of the mass and specific heat of the fluid and the measured temperature rise. The calculated heating value must, however, be corrected to account for heat losses mainly by conduction through the container wall, to the surrounding of the device. In modern calorimetery, the corrections are 
made automatically using sensors and controllers. The measured heating value is considered as a gross value at constant volume because the biomass combustion in the container has taken place inside the fixed volume of the container. Taking this into account, the resulting gross heating value is determined based on dry mass content of the sample biomass using the expression

$$
\mathrm{HHV}_{d}=\frac{\mathrm{HHV}}{1-M}
$$

where $\mathrm{HHV}_{d}$ is the gross heating value of the biomass in $\mathrm{MJ} / \mathrm{kg}$ of dry biomass, $\mathrm{HHV}$ is the gross heating value determined by the calorimeter, and $M$ is the moisture content of the biomass in decimal wet mass fraction.

Alternatively, the high heating values can also be estimated if the chemical composition of the fuel samples is known using the expression [2]

$$
\begin{aligned}
\mathrm{HHV}_{d}= & 0.35 X_{\mathrm{C}}+1.18 X_{\mathrm{H}}+0.10 X_{\mathrm{S}} \\
& +0.02 X_{\mathrm{N}}+0.10 X_{\mathrm{O}}+0.02 X_{\mathrm{ash}},
\end{aligned}
$$

where $X$ is the mass fractions (percent mass dry basis) for carbon $C$, hydrogen $(H)$, sulfur $(S)$, nitrogen $(N)$, oxygen $(O)$, and ash content (ash). The unit of $\mathrm{HHV}_{d}$ in (2) is in MJ/kg dry mass, and it shows how the presence of carbon, hydrogen, and sulfur elements in the biomass would have an effect (increase) the heating value, whereas the presence of nitrogen, oxygen, and ash elements in biomass is likely to suppress the heating value.

The determination of chemical composition of the feedstock materials is made by conducting materials characterization performed on pure coffee and rice husks samples, applying both proximate and ultimate analysis methods. This is important since the heating value of biomass is highly correlated with the content of ash and volatiles, including the elemental composition of carbon, hydrogen, and oxygen [3]. Proximate analysis involved the determination of moisture, volatile matter, fixed carbon, and ash contents made in accordance to specified ASTM standards applicable for the determination of individual components of the respective samples. The determination of fixed carbon composition was later made by taking the difference. On the other hand, ultimate analysis was conducted to determine carbon, hydrogen, nitrogen, and sulphur ( $\mathrm{C}, \mathrm{H}, \mathrm{N}$, and $\mathrm{S})$ contents in the materials based also on prescribed ASTM standard methods, using the atomic absorption spectrometer (AAS) also available at the University of Dar es Salaam. For this case, the oxygen $(\mathrm{O})$ content is also calculated by difference.

\subsection{Thermal Degradation Characteristics Determination.} Thermogravimetric analysis, which is a standard procedure for determining mass loss characteristics of biomass materials when heated at prescribed rates, was conducted for all five blended samples including two for pure rice and coffee husks samples. During thermal degradation analysis,30 mg of each sample was analyzed under inert nitrogen $(99.95 \%$ purity) condition using a simultaneous thermal gravimetric analyzer (TG) model: NETZSCH STA 409 PC Luxx, available at the Energy Engineering and Sciences Laboratory. The prescribed heating rate used for this study was $10^{\circ} \mathrm{C} /$ minute, and the samples were heated from ambient temperature to $1000^{\circ} \mathrm{C}$.

The TG analyzer consists of a furnace with a reaction chamber, microbalance chamber, control panel, and data acquisition system. TG combines both the heat flux differential scanning calorimeter (DSC) that characterizes physical and chemical processes related to thermal effect while the TG measures mass changes due to materials evaporation, decomposition, and interactions that occur within the furnace atmosphere. The operating principles of the DSC include use of a sample crucible together with an empty reference crucible put into the furnace heated at a constant heating rate. The crucibles are placed on a heat flux sensor that records the difference in heat flow between them and the measurement is recorded in form of a signal used to determine the targeted material's properties. The sensor is coupled to a PC installed with special and user friendly Proteus software utilized for data acquisition, storage, and analysis. A typical experimental arrangement of the equipment is shown in Figure 1.

\section{Results and Discussion}

3.1. Feedstock Materials Characteristic Properties. As can be seen in Table 3, coffee husks exhibit better energy quality than rice husks, where the heating value for coffee husks is recorded to be higher $(18.34 \mathrm{MJ} / \mathrm{kg})$ compared to that of rice husks (13.24 MJ/kg). Similarly, there are more volatiles in coffee husks than in rice husks in which their respective values are 83.20 and $59.20 \%$. On the other hand, rice husks exhibited high ash content reaching $26.20 \%$, almost ten times higher than that of coffee husks $(2.50 \%)$. The existence of high ash content in rice husks is one of the degrading factors that would contribute negatively to its energy content [46]. Furthermore, the high ash content is detrimental to thermochemical processes since it is responsible for equipment's fouling and corrosion $[3,7]$.

The results obtained based on the analysis made on these materials suggest these materials to have acceptable heating values and high content of volatiles, carbon, hydrogen, and oxygen. However, the materials have relatively low content of nitrogen, sulphur, and chlorine, which is a typical characteristic of biomass.

\subsection{Thermal Degradation Characteristics of Blend Materials}

3.2.1. Thermogravimetric Analysis Results. Thermogravimetric analysis results presented in Table 4 show that blending coffee husks with rice husks improves the degradation characteristics. In this study, when pure rice husks were analyzed after $1000^{\circ} \mathrm{C}$, the remaining char and ash (residue mass) was $26.50 \%$, whereas this amount is reduced linearly as coffee husks content is increased. When $25 \%$ of rice husks were blended with $75 \%$ of coffee husks, the lowest residual mass of about $23.65 \%$ was yielded. This blending ratio is therefore considered to offer optimal residue mass reduction with reference to the degradation characteristics as seen in the corresponding TG thermograms shown in Figure 2. 


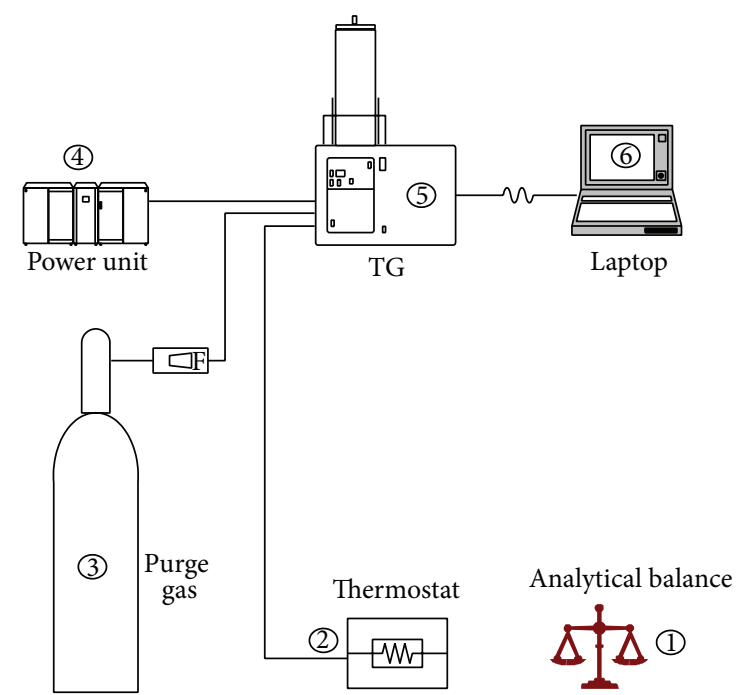

FIGURE 1: Thermogravimetric experimental measurements arrangement.

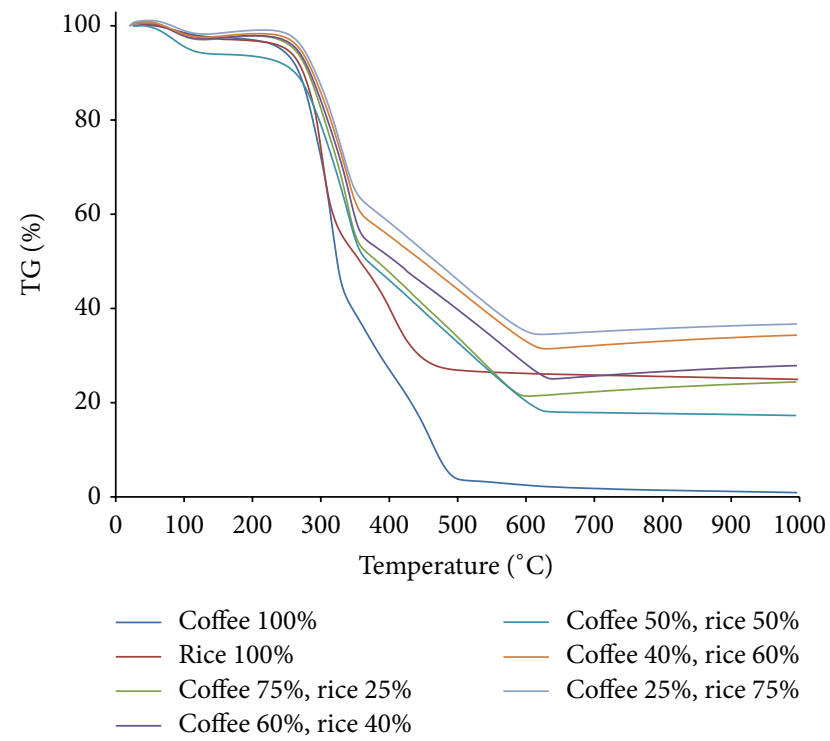

FIGURE 2: Thermogravimetric profiles for pure and blended samples.

3.2.2. Derivative Thermogravimetric Analysis for Pure and Blended Samples. Analysis of derivative thermogravimetric DTG curves made produced results summarized in Table 5 and shown in Figure 3. These results suggest that hemicellulose and cellulose peaks for coffee and rice husks are comparably close with values of -11.5 and -11.2 and -3.20 and -2.90 , respectively. Coffee husks being relatively more reactive, their peaks occur at a later stage than rice husks. Blending coffee and rice husks reduced the hemicellulose and cellulose peaks to almost the half of their parent samples, and the peak temperatures are shifted to higher temperatures. These results show hemicellulose peaks to be higher in all blended materials than it is the case for pure coffee and rice husk samples. Similarly, results show cellulose peaks in the blended materials to be higher than in pure rice

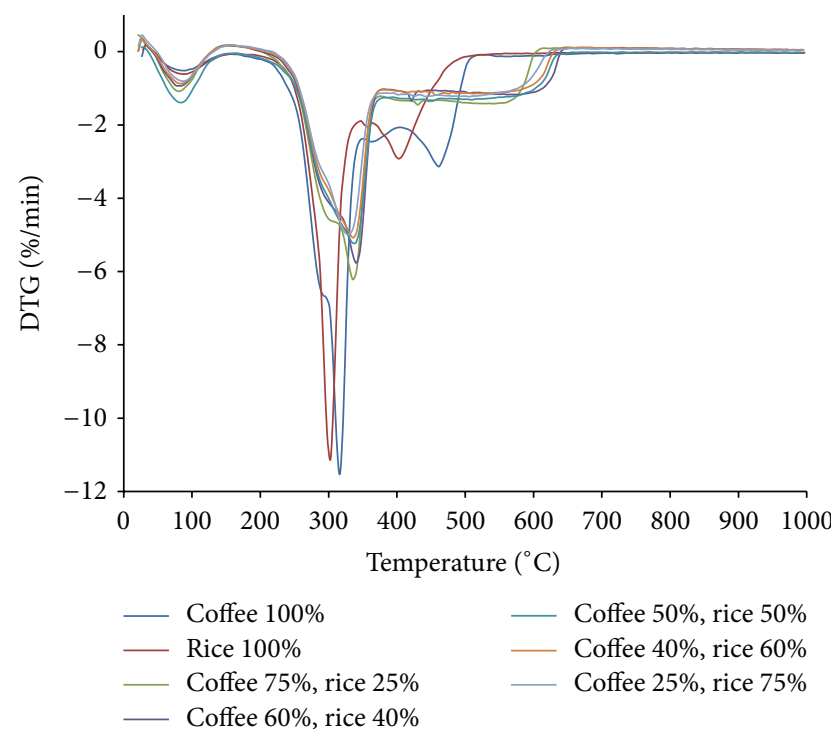

FIGURE 3: Derivative thermograms for pure and blended samples.

TABLE 3: Proximate and ultimate analysis of coffee and rice husks.

\begin{tabular}{lcc}
\hline Analysis methods & Rice husks & Coffee husks \\
\hline $\begin{array}{l}\text { (1) Proximate Analysis (\%), } \\
\quad \text { dry basis }\end{array}$ & \\
$\quad$ Moisture & 8.80 & \\
Volatile matter & 59.20 & 6.70 \\
Fixed carbon & 14.60 & 14.30 \\
Ash & 26.20 & 2.50 \\
(2) Ultimate Analysis (\%), & & \\
dry basis & & \\
C & 45.60 & 49.40 \\
H & 4.50 & 6.10 \\
N & 0.19 & 0.81 \\
O & 33.40 & 41.20 \\
Cl & 0.08 & 0.03 \\
S & 0.02 & 0.07 \\
Higher heating value & 13.24 & 18.34 \\
(MJ/kg) & &
\end{tabular}

TABLE 4: Thermogravimetric characteristics of coffee and rice husks blends.

\begin{tabular}{lcccc}
\hline \multirow{2}{*}{ S/N } & \multirow{2}{*}{ Material } & \multicolumn{2}{c}{ Mass loss, \% } & Moisture \\
& & $\begin{array}{c}\text { Volatiles } \\
\text { released }\end{array}$ & $\begin{array}{c}\text { Remaining } \\
\text { rhar and ash }\end{array}$ \\
\hline 1 & Coffee 25\% rice 75\% & 2.48 & 64.04 & 33.48 \\
2 & Coffee 40\% rice 60\% & 2.97 & 66.17 & 30.86 \\
3 & Coffee 50\% rice 50\% & 3.08 & 72.87 & 24.05 \\
4 & Coffee 60\% rice 40\% & 3.23 & 72.27 & 24.50 \\
5 & Coffee 75\% rice 25\% & 3.52 & 72.83 & 23.65 \\
6 & Coffee 100\% & 2.66 & 92.13 & 5.21 \\
7 & Rice 100\% & 3.01 & 70.49 & 26.50 \\
\hline
\end{tabular}


TABle 5: Degradation characteristics of coffee and rice husks blends.

\begin{tabular}{|c|c|c|c|c|c|}
\hline \multirow{2}{*}{$\mathrm{S} / \mathrm{N}$} & \multirow{2}{*}{ Material } & \multicolumn{2}{|c|}{ Hemicellulose peak } & \multicolumn{2}{|c|}{ Cellulose peak } \\
\hline & & Max. rate $(\% / \mathrm{min})$ & Peak temp. $\left({ }^{\circ} \mathrm{C}\right)$ & Max. rate $(\% / \mathrm{min})$ & Peak temp. $\left({ }^{\circ} \mathrm{C}\right)$ \\
\hline 1 & Coffee $25 \%$, rice $75 \%$ & -5.0 & 330 & -1.23 & 506 \\
\hline 2 & Coffee $40 \%$, rice $60 \%$ & -5.2 & 336 & -1.22 & 458 \\
\hline 3 & Coffee $50 \%$, rice $50 \%$ & -5.2 & 338 & -1.33 & 450 \\
\hline 4 & Coffee $60 \%$, rice $40 \%$ & -5.3 & 340 & -1.36 & 422 \\
\hline 5 & Coffee $75 \%$, rice $25 \%$ & -6.2 & 336 & -1.45 & 431 \\
\hline 6 & Coffee $100 \%$ & -11.5 & 316 & -3.20 & 461 \\
\hline 7 & Rice $100 \%$ & -11.2 & 310 & -2.90 & 403 \\
\hline
\end{tabular}

husk but comparably close to pure coffee husks. Use of coffee and rice husks blends in high temperature gasification process would have an effect on the reduction of the latter's flammability while at the same time increasing its flame retention characteristics, hence offering the opportunity for the production of clean syngas in a sustainable manner.

The combined derivative thermograms (DTG) showed in Figure 3 represent profiles of the rate of mass loss (degradation rate) of the biomass materials samples which are usually characterized with two peaks. The first peak to the left represents hemicellulose whereas the one to the right is for the cellulose $[8,9]$. Lignin usually decomposes slowly with unnoticeable tailing peak to the extreme right of the thermogram [10].

\section{Conclusion}

Tanzania is considered to have a satisfactory amount of agricultural residues and also enough unutilized and low-value land that could be used for ligneous feedstock production. The study has examined energy characteristics of agricultural residues originating from rice and coffee husks that are readily available in Tanzania in vast amounts that offer the opportunity in the development of the second generation biofuels sector.

The results obtained based on the analysis made on these materials suggest these materials to have acceptable heating values and high content of volatiles, carbon, hydrogen, and oxygen. The materials have also relatively low content of nitrogen, sulphur, and chlorine which is typical of biomass. However, rice husks are exhibited to have ash content, which is one of the degrading factors that would contribute negatively to its energy content, leaving high combustion residue.

The analysis made on rice and coffee husks blends improved the thermal degradation characteristics and yielded the lowest residual mass (char and ash). These results suggest that use of coffee and rice husks blends in high temperature gasification process (at $1000^{\circ} \mathrm{C}$,) would also have an effect on the reduction of the latter's flammability while at the same time increasing its flame retention characteristics in a sustainable manner. Hence, the study results based on derivative thermogravimetric analysis have established the materials' suitability in applying high temperature.

The study has demonstrated the viability of using agricultural wastes, forest residue, and a number of fast growing trees, grown specifically for energy purposes in Tanzania, offering the opportunity in the development of the second generation biofuels sector. However, the energy content of several different biomass materials differs depending on the level of its moisture content. In order to limit excessive moisture (above 20\%) that deteriorates the performance of gasifiers, it is necessary to deploy secondary processing like drying (possibly using process waste heat). Conversion of biomass to gaseous or liquid form of energy is known to be easier to handle and make applications.

\section{Conflict of Interests}

The author declares that there is no conflict of interests regarding the publication of this paper.

\section{References}

[1] Ministry of Agriculture Food Security and The United Republic of Tanzania, “Agriculture Sector Development," 2001.

[2] S. Gaur and T. B. Reed, Thermal Data for Natural and Synthetic Fuels, Marcel Dekker, NewYork, NY, USA, 1998.

[3] I. Obernberger, F. Biedermann, W. Widmann, and R. Riedl, "Concentrations of inorganic elements in biomass fuels and recovery in the different ash fractions," Biomass \& Bioenergy, vol. 12, no. 3, pp. 211-224, 1997.

[4] W. J. Chancellor, C. N. Thai, and T. W. Lin, "Potential of char for marketing agricultural residue energy," ASAE Paper 81-3054, American Society of Agricultural Engineers, St. Joseph, Mich, USA, 1981.

[5] B. M. Jenkins and J. M. Ebeling, "Correlation of physical properties of terrestrial biomass with conversion," in Proceedings of the 10th Energy from Biomass and Wastes, Institute of Gas Technology, Chicago, Ill, USA, 1985.

[6] A. Faaij, J. van Doorn, T. Curvers et al., "Characteristics and availability of biomass waste and residues in the Netherlands for gasification," Biomass \& Bioenergy, vol. 12, no. 4, pp. 225$240,1997$.

[7] D. Vamvuka and D. Zografos, "Predicting the behaviour of ash from agricultural wastes during combustion," Fuel, vol. 83, no. 14-15, pp. 2051-2057, 2004.

[8] V. Cozzani, L. Petarca, and L. Tognotti, "Devolatilization and pyrolysis of refuse derived fuels: characterization and kinetic modelling by a thermogravimetric and calorimetric approach," Fuel, vol. 74, no. 6, pp. 903-912, 1995. 
[9] J. M. Heikkinen, J. C. Hordijk, W. de Jong, and H. Spliethoff, "Thermogravimetry as a tool to classify waste components to be used for energy generation," Journal of Analytical and Applied Pyrolysis, vol. 71, no. 2, pp. 883-900, 2004.

[10] A. J. Tsamba, W. Yang, and W. Blasiak, "Pyrolysis characteristics and global kinetics of coconut and cashew nut shells," Fuel Processing Technology, vol. 87, no. 6, pp. 523-530, 2006. 

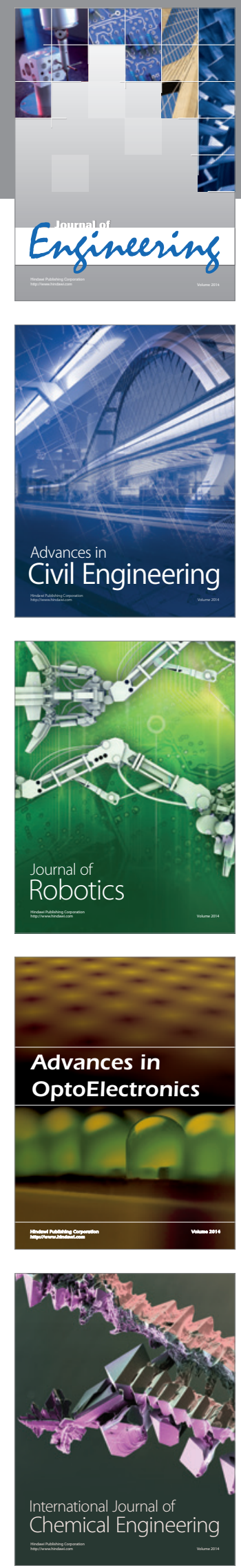

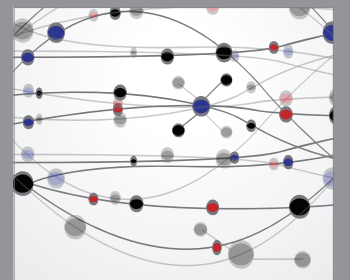

The Scientific World Journal
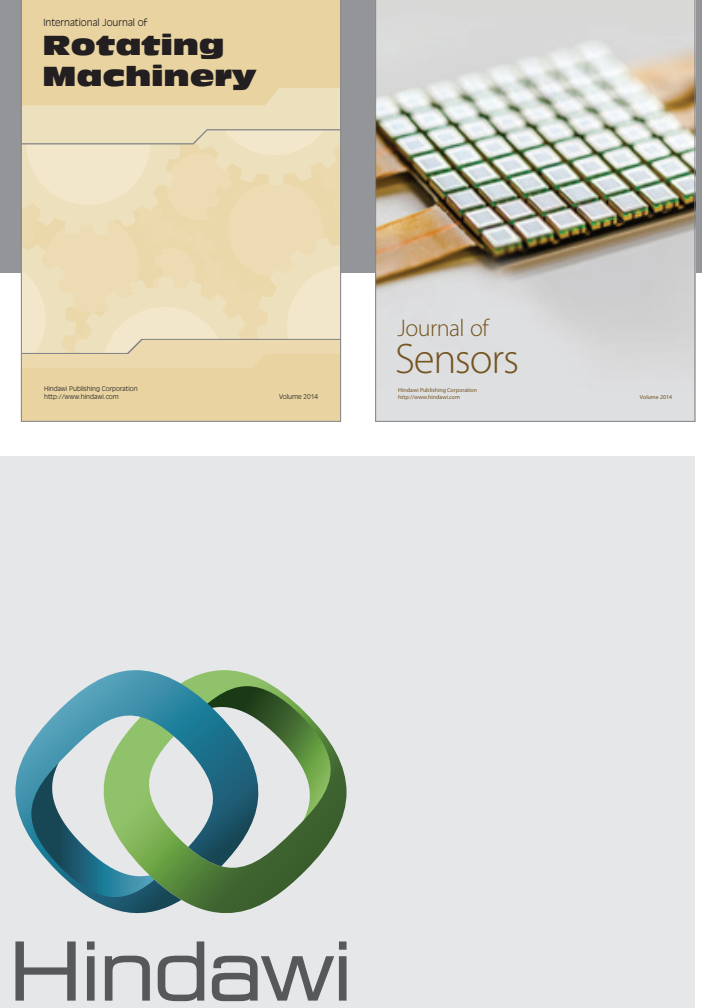

Submit your manuscripts at http://www.hindawi.com
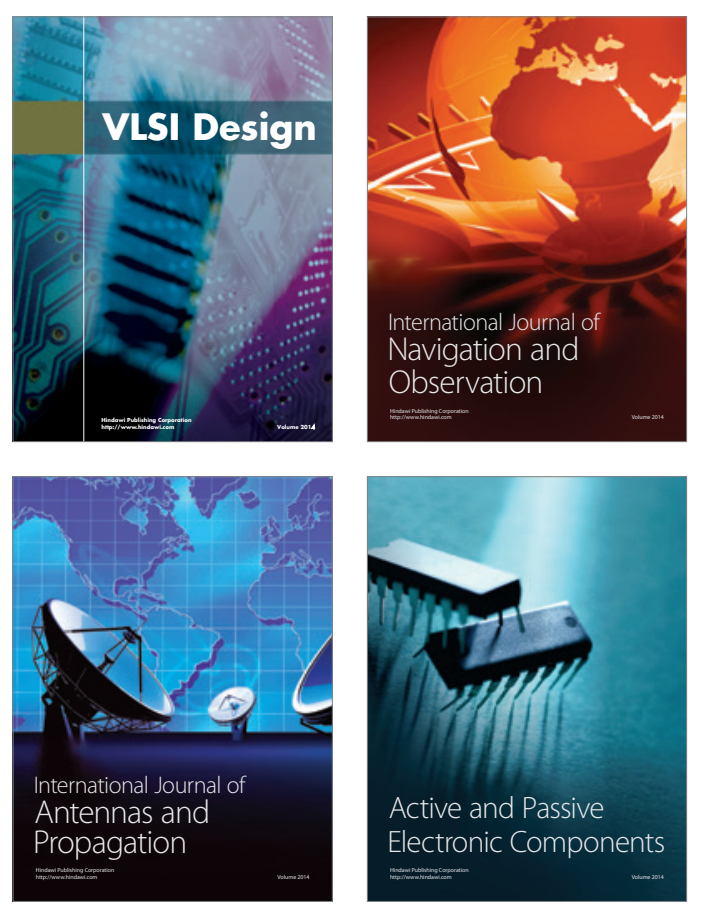
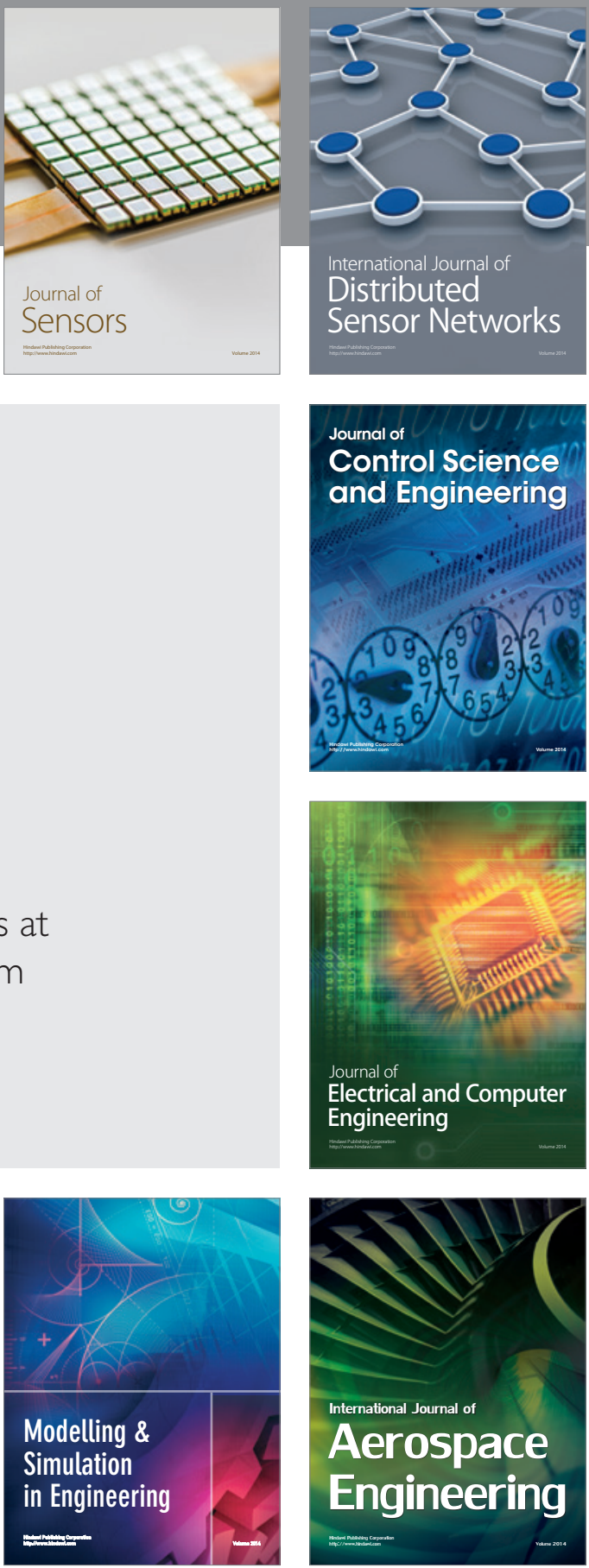

Journal of

Control Science

and Engineering
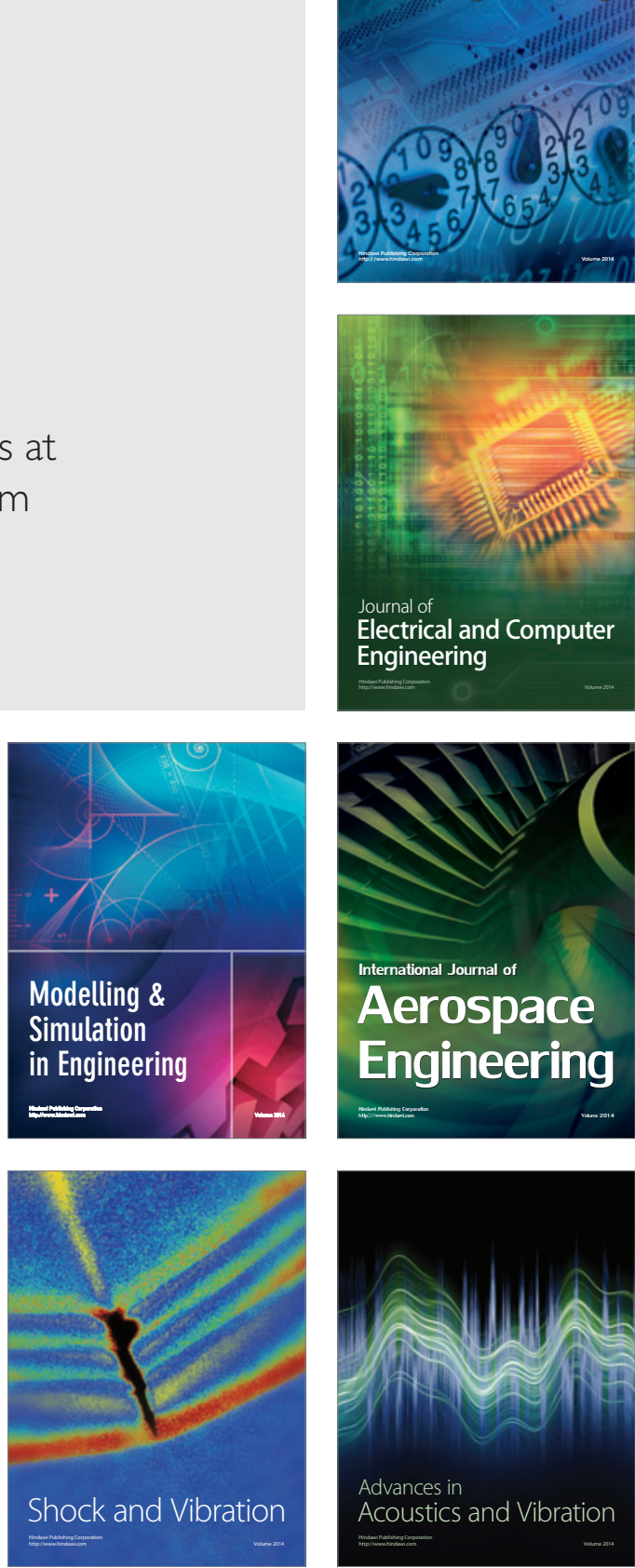